\title{
The SYNTAX score and the coronary artery calcium score for the prediction of clinical outcomes in patients undergoing percutaneous coronary intervention
}

\author{
Yaocong RONG ${ }^{1}$, Tianqi $\mathrm{LI}^{1}$, Yang $\mathrm{CHEN}^{1}$, Hongyuan $\mathrm{LIU}^{1}$, Weilin $\mathrm{HONG}^{1}$, Shaofeng GUAN ${ }^{1}$, Wenzheng HAN ${ }^{1}$, \\ Qian $\mathrm{GAN}^{1}$, Liang ZHANG ${ }^{1}$, Xifeng $\mathrm{CHANG}^{1}$, Chengqi KONG${ }^{1}$, Tingwen WENG ${ }^{1}$, Chuan $\mathrm{SHI}^{1}$, Youjun $\mathrm{ZHANG}^{1}$, \\ Xinkai QU ${ }^{1 *}$
}

\begin{abstract}
This study aims to investigate the predictive value of SYNTAX score,SYNTAX score II and coronary artery calcium score on the prognosis of patients after PCI. The SYNTAX score, SYNTAX score II and coronary artery calcium score were calculated. The primary end point was major adverse cardiac and cerebrovascular events (MACCE). 195 patients were included, 182 patients were followed up and the median follow-up time was 34.5 months. The MACCE occurred in 30 patients. The incidence of MACCE of lower risk, medium risk and high risk were: SYNTAX score: $6.7 \%, 18.3 \%, 24.2 \%$; coronary artery calcium score: 9.7\%, 18.3\%, 21.7\%; SYNTAX score II: 6.6\%, 16.4\%, 26.7\%; new combined risk score: $7.7 \%, 8.1 \%$, and $35.8 \%$. ROC analysis showed that SYNTAX score (AUC: $0.641,95 \%$ CI: 0.540-0.743), coronary artery calcium score (AUC: $0.597,95 \%$ CI: 0.490 -0.704), SYNTAX score II (AUC: $0.662,95 \%$ CI: 0.561 - 0.763), new combined risk score (0.711, 95\%CI: 0.606 - 0.816). The new combined risk score tended to be superior compared to other risk score $(\mathrm{p}<0.01)$. The results suggested that SYNTAX score, SYNTAX score II and new combined risk score can predict the occurrence of MACCE after PCI, new combined risk score provides superior prediction.
\end{abstract}

Keywords: SYNTAX score; SYNTAX score II; Coronary artery calcium score; percutaneous coronary intervention; major adverse cardiac and cerebrovascular events.

Practical Application: Predictive value of SYNTAX score,SYNTAX score II and coronary artery calcium score on the prognosis of patients after PCI.

\section{Introduction}

Coronary artery disease (CAD) is one of the major cardiovascular diseases affecting the global human population (Malakar et al., 2019). The main treatment for patients with coronary heart disease is coronary revascularization. Percutaneous coronary intervention (PCI) and coronary artery bypass graft (CABG) are two important methods of myocardial revascularization (Choi et al., 2019; Hogan et al., 2020). At present, PCI is becoming more and more common in clinical applications due to its small trauma, significant therapeutic effect, few postoperative complications, short operation time, and fast postoperative recovery. However, there are also clinical studies that have found that some patients have poor long-term prognosis after PCI treatment (Na et al., 2018; Matsuo et al., 2018). It is an important issue for coronary heart disease intervention doctors to find the superior population of PCI for precise treatment.

SYNTAX score is a score system based on coronary angiography showing coronary anatomy results for evaluating the complexity of coronary artery disease (Sianos et al., 2005), SYNTAX trial (Serruys et al., 2009) by comparing PCI and CABG to treat three coronary heart disease lesions and the left main differences in clinical outcomes after lesions were intended to guide clinicians in choosing the optimal revascularization method. Therefore, the European and American guidelines for coronary revascularization recommend the use of SYNTAX scores to guide CABG or PCI surgery in patients with coronary heart disease (Wijns et al., 2010; Yancy et al., 2013). Since then, the SYNTAX study and a large number of clinical studies have shown that the SYNTAX score has a certain predictive value for the prognosis of patients after PCI (Karabağ et al., 2018; Ikeno et al., 2017). A new scoring method -SYNTAX score II was reported in 2013 (Farooq et al., 2013). SYNTAX score II includes gender, age, left ventricular ejection fraction, serum creatinine clearance, left main disease, chronic obstructive pulmonary disease, peripheral vascular disease. Compared with SYNTAX score, SYNTAX II is more comprehensive and individualized. In addition, previous study also reported that the SYNTAX score II has predictive value for the long-term mortality of patients with left main disease after PCI (Xu et al., 2014). However, most of the current studies on SYNTAX score and SYNTAX score II are from European and American countries, and there are few domestic studies.

Coronary artery calcium score (CACS) is a more commonly used scoring system that uses computerized tomography (CT) technology to quantitatively evaluate plaque load and calcium, including Agatston score and calcium volume score (Mizuiri et al., 2018). Many studies believe that it can be used as an important predictor of cardiovascular prognosis and guide

*Corresponding author: xinkaiqu20@sina.com 
the development of cardiac revascularization strategies ( $\mathrm{Al}$ Rifai et al., 2015; Clerc et al., 2020). Early study has shown that coronary calcium score combined with risk factors can better predict the prognostic value of asymptomatic patients than single methods, and can more accurately guide the first-stage prevention strategy of people with coronary heart disease risk factors (Greenland et al., 2004). Therefore, we speculate that SYNTAX score combined with coronary artery calcium score may improve the accuracy of adverse event prediction.

The accuracy of the PCI postoperative risk prediction integral model can quantify the risk, which helps to better evaluate the risk of PCI treatment and better formulate the most optimal treatment strategy. This study mainly explored the predictive value of SYNTAX score, SYNTAX score II and coronary calcium score based on Multislice CT (MSCT) on the prognosis of PCI patients, and established the score system by combined SYNTAX score with coronary calcium to evaluate the coronary artery Severity, and explore whether it is more objective and accurate.

\section{Material and methods}

\subsection{Inclusion and exclusion criteria of objects}

This study retrospectively analyzed 195 patients who underwent coronary angiography and coronary therapy with coronary angiography at East China Hospital Affiliated to Fudan University from January 2012 to March 2014. All patients underwent coronary CT angiography within 3 months before surgery.

Inclusion criteria: unlimited clinical manifestations, including stable angina, unstable angina and non-ST-segment elevation acute myocardial infarction. The characteristics and location of coronary artery disease were not limited, including left main disease and non-left main disease, bifurcation disease, chronic complete occlusion, calcium disease, etc. All patients were implanted with drug-coated stents.

Exclusion criteria: Allergy to contrast media, previous history of CABG or PCI. Patients with severe organ dysfunction, cardiogenic shock, severe infection, cerebrovascular accident or malignant tumor. Children, pregnant and lactating women.

\subsection{Collection of clinical data}

The patient's name, gender, age, height, body mass index, triglycerides, low density lipoprotein, high density lipoprotein, serum creatinine, alanine aminotransferase, aspartate aminotransferase, glycated hemoglobin, and left ventricular injection blood fraction, were collected. The patient's recent smoking history, hypertension, diabetes, abnormal blood lipid metabolism, chronic obstructive pulmonary disease, peripheral vascular disease and other medical history and clinical diagnosis, oral medication and other general information were recorded. The diagnosis of hypertension was=s based on the WHO/ISH guidelines: 1) Those who have a clear history of hypertension and have been treated for hypertension; 2) Those who have not taken antihypertensive drugs, are measured with a mercury sphygmomanometer, when they are not on the same day for two times of systolic blood pressure $\geq 140 \mathrm{mmHg}$ or diastolic blood pressure $\geq 90 \mathrm{mmHg}$. Diabetes according to the diagnostic criteria of the American Diabetes Association (ADA) in 1997: 1)Those who have a clear history of diabetes or have taken hypoglycemic drugs or insulin injection therapy; 2)Patients with plasma glucose $\geq 11.1 \mathrm{mmol} / \mathrm{L}$ at any time, fasting blood glucose $\geq 7.0 \mathrm{mmol} / \mathrm{L}$ twice, and glucose $\geq 11.1 \mathrm{mmol} / \mathrm{L} 2$ hours after a glucose tolerance test meal., those without typical symptoms must be retested on another day. Dyslipidemia: total cholesterol (TC) $\geq 5.2 \mathrm{mmol} / \mathrm{L}$ or triglyceride $(\mathrm{TG}) \geq 1.7 \mathrm{mmol} / \mathrm{L}$ or low density lipoprotein cholesterol (LDL-C) $>2.26 \mathrm{mmol} / \mathrm{L}$ or high density Lipoprotein cholesterol (HDL-C) $<1.04 \mathrm{mmol} / \mathrm{L}$. Smoking is defined as daily smoking volume $>10$ cigarettes, and continuous smoking time $>1$ year. Body mass index (BMI) is calculated based on weight/height squared $\left(\mathrm{kg} / \mathrm{m}^{2}\right)$. COPD diagnostic criteria: 1)Have a clear history of chronic obstructive pulmonary disease; 2)Have chronic cough, expectoration $>3$ months, progressive dyspnea, lung function test FEV1/FVC $<0.70$. Peripheral vascular disease: there is a clear arterial operation other than coronary arteries history of treatment or drug therapy. Carotid artery and extremity blood vessels on admission routinely indicated that the degree of arterial stenosis was $\geq 50 \%$; the cardiac ultrasound diagnostic instrument is PHILIPS IE33 ultrasound instrument, with a probe frequency of 1-5 MHz, and the subject is instructed to use the left lateral position. The probe is aimed at the position of the apex of the subject, the left ventricular end systolic diameter (LVESD) and the left and right ventricular end diastolic diameter (LVDD) of the subject are measured, and the left ventricular ejection fraction (LVEF) is measured using a biplane Simpason method, followed by two-chamber measurement and apical four-chamber measurement. The subject's diastolic positive bimodal blood flow spectrum was collected. The early and late diastolic peak flow velocity were measured and recorded respectively, and recorded as $\mathrm{E}$ peak and A peak value, E/A value.

\subsection{Coronary angiography}

The enrolled PCI patients received dual antiplatelet aggregation therapy before surgery. For elective PCI patients, clopidogrel bisulfate $75 \mathrm{mg} /$ day (mg/day) and aspirin $100 \mathrm{mg} /$ day (mg/day) were given 24 hours before surgery. For patients with direct PCI, antiplatelet aggregation loading dose of $300 \mathrm{mg}$ aspirin and $300 \mathrm{mg}$ clopidogrel bisulfate were given immediately after admission. Siemens' digital subtraction angiography X-ray machine (SIEMENS AXIOM Artis Zee Biplane MN) was used. It was located at the right or left radial artery (right femoral artery if necessary), routine disinfection and draping, $1 \%$ lidocaine local anesthesia puncture point. The radial artery was punctured by the Seldinger method, a $6 \mathrm{~F}$ arterial sheath was inserted, the contrast injection rate was $6 \mathrm{ml} / \mathrm{s}$, and the injection was uniform and consistent. Onepac (Iohexol injection 350mg I/mL, General Electric Pharmaceutical) was used as a contrast agent. The frame of the contrast image was 15 frames per second so that the coronary artery can be clearly displayed. The contrast transillumination position included at least 8 groups of standard projection planes (5 groups in the left crown and 3 groups in the right crown). When the judgment of the lesion was the same as that of the two interventional physicians, it was 
regarded as the final coronary angiography result. According to the surgical records, the patient's lesion location, number, bifurcation lesion, chronic complete occlusive lesion, and the number of stents placed during surgery were collected. The use of unfractionated heparin and glycoprotein IIb/IIIa inhibitors during the operation, the choice of stenting strategy, and the duration of postoperative dual antiplatelet aggregation treatment were determined by the interventional cardiologist (Figure 1).

\subsection{SYNTAX score}

The SYNTAX score adopted the coronary artery tree 16-segment method revised by the American Heart Association. There were 12 variables, such as lesion location, characteristics, and stenosis. The total score of the lesions with diameter $\geq 1.5 \mathrm{~mm}$ and stenosis $\geq 50 \%$ was SYNTAX scores. According to the PCI data of the patients, the SYNTAX scores of the patients were calculated on the SYNTAX scores website (www.syntaxscore. com). At the same time, combined with age, gender, serum creatinine, left ventricular ejection fraction, whether it was left main disease, whether it was combined with the history of peripheral vascular disease and chronic obstructive pulmonary disease, the SYNTAX score II was automatically calculated by the above SYNTAX score website.

\subsection{Coronary artery calcium score}

GE LightSpeed 64-slice CT, retrospective ECG-gated helical scanning technology were used for coronary artery image acquisition, the scanning range started from below the trachea protuberance to $10 \mathrm{~mm}$ below the heart septum, the entire heart scan was completed in one breath, and the data was stored AW4.4 image processing workstation. Scanning parameters: layer thickness $0.625 \mathrm{~mm}$, tube voltage $120 \mathrm{KV}$, tube current $70 \mathrm{~mA}$, scanning time $260 \mathrm{~ms} / \mathrm{r}$, matrix $512 \times 512$, field of view $25 \mathrm{~cm}$. According to the results of coronary CT angiography, the patient's lesion location and calcium score were recorded, and Agatston score was used. In the AW4.4 image workstation, the SmartScore3.5 software was used as the basic unit of integration in the AJ-350 mode. The calcium of the CT value between $130-199 \mathrm{Hu}$ was defined as 1 , the calcium between $200-299 \mathrm{Hu}$ was defined as 2, the calcium between $300-399 \mathrm{Hu}$ was defined
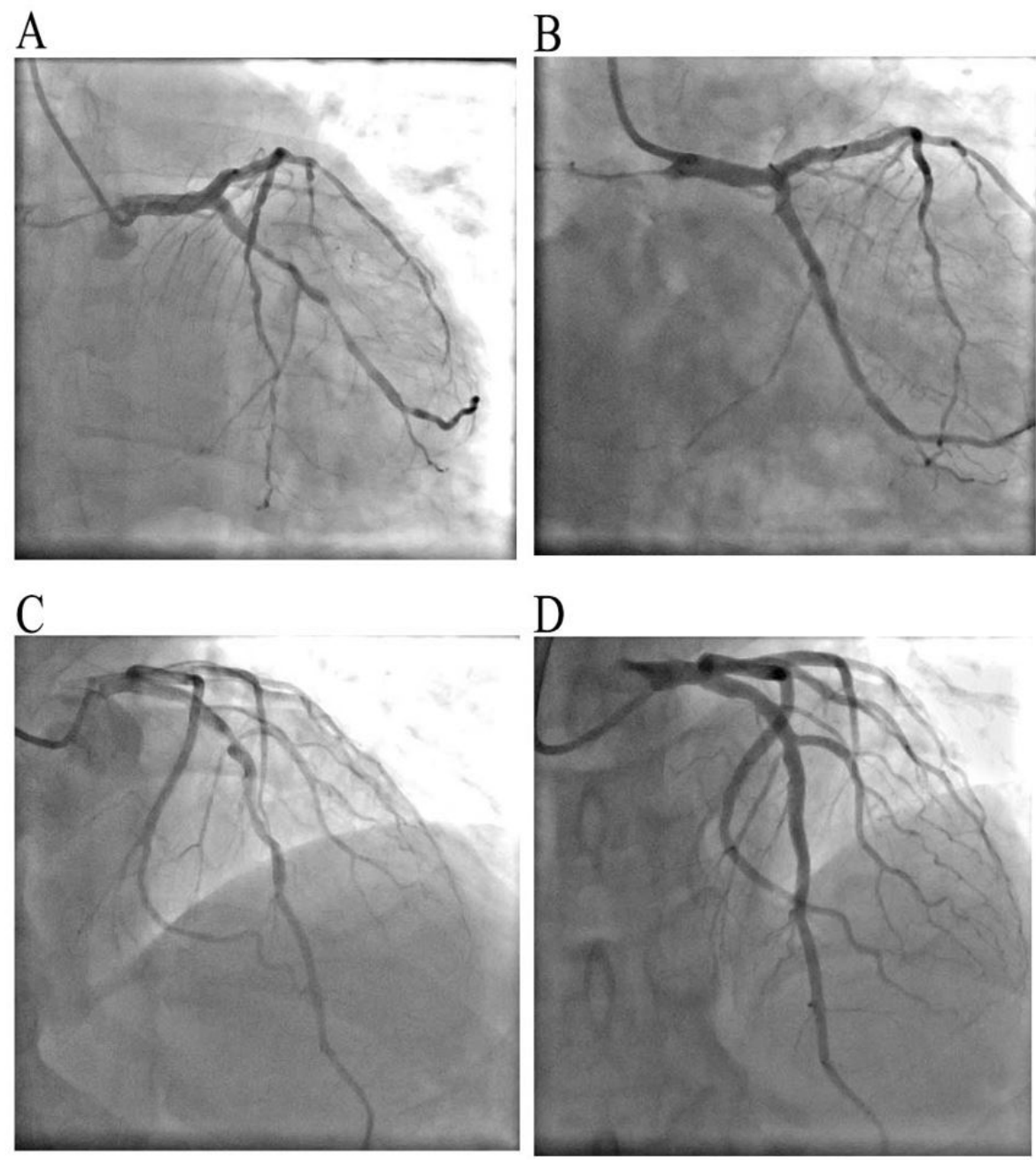

Figure 1. Left circumflex branch long lesion, stenosis 50-80\% (A). Left circumflex artery after PCI(B). Bifurcation lesion of left anterior descending branch(C). Left anterior descending branch and diagonal branch after PCI(D). 
as 3 , and the calcium of $400 \mathrm{Hu}$ and above was defined as 4 . The total coronary calcium score was determined by the product of the peak score and the calcium area and the distribution of calcified blood vessels (Figure 2).

\subsection{Postoperative follow-up}

From January 2015 to April 2017, all patients were discharged from the hospital by telephone, outpatient visit records, or follow-up hospitalization related medical records (some patients rechecked coronary angiography 1 year after surgery). Drug use including aspirin, P2Y12 receptor inhibitors, statin lipidlowering drugs, $\beta$-blockers, angiotensin converting enzyme inhibitors or angiotensin converting enzyme inhibitor (ACEI, Angiotensin II receptor antagonist (ARB) drugs, and the type and timing of major adverse cerebro-cardiovascular events (MACCE) were recorded.

\subsection{Definition of outcome indicators}

The main outcome indicator of this study was MACCE, including all-cause death, non-fatal myocardial infarction (MI), unplanned coronary revascularization, and stroke. The secondary outcome indicators were all-cause death, cardiogenic death, non-fatal myocardial infarction, and unplanned coronary revascularization. All deaths were considered to be of cardiac origin, unless it can be clearly the cause of non-cardiac death. Myocardial infarction was defined as an increase in the concentration of myocardial infarction markers greater than three times the upper limit of the normal reference value and dynamic changes, accompanied by one of the following conditions: 1) Imaging evidence suggested the loss of surviving myocardium or the emergence of segmental wall motion abnormalities; 2) Electrocardiograms suggested new ischemic changes in myocardium;3) Associated with symptoms of myocardial ischemia. Unplanned coronary revascularization was defined as unplanned rehospitalization for coronary revascularization (PCI or CABG). Stroke referred to a bloody or ischemic stroke.

\subsection{Statistical analysis}

In this study, SPSS20.0 software was used for statistical processing and analysis. The measurement data conformed to the normal distribution and was expressed by the mean \pm standard deviation. If it did not conform to the normal distribution, it was expressed by the median and interquartile range. Kolmogorov-Smirnov was used for normality test. Normal distribution data were analyzed by one-way analysis of variance or T test for independent samples. Otherwise, rank sum test was used; count data was expressed by frequency and percentage. Chi-square test or FISH exact test was used for comparison between groups. The ROC curve $\mathrm{Z}$ test was used to compare the MACCE prediction capabilities of different integration systems. Area under curve (AUC) was expressed as $95 \%$ confidence interval (CI). Kaplan-Meier curve and Log-rank test were used to compare the occurrence of major adverse cardiovascular and cerebrovascular events in each group. $\mathrm{P}<0.05$ was considered statistically significant in two-sided test.

\section{Results}

\subsection{Baseline data, contrast characteristics and comparison between groups in the study population}

A total of 195 patients were included in this study. A total of 182 patients completed follow-up, with an average age of 68.4 \pm 9.4 years. Among them, male patients accounted for $71.4 \%$ (130 cases). Diabetes, hypertension, and abnormal blood lipid metabolism accounted for $26.9 \%$ (49 cases), $75.2 \%$ (137 cases), and $18.1 \%$ (33 cases), respectively. 33\% (60 patients) were smokers.

For clinical manifestations, $43.4 \%$ (79 cases) were stable angina, and the rest were acute coronary syndromes, including $45.6 \%$ (83 cases) of unstable angina, $11 \%$ (20 cases) of acute non-ST segment elevation type myocardial infarction. Among them, patients with three branch lesions accounted for 19.8\% (36 cases), two branch lesions accounted for $37.4 \%$ (68 cases), and single branch lesions accounted for $42.8 \%$ (78 cases). Left main patients accounted for $8.8 \%$ (16 cases), left anterior
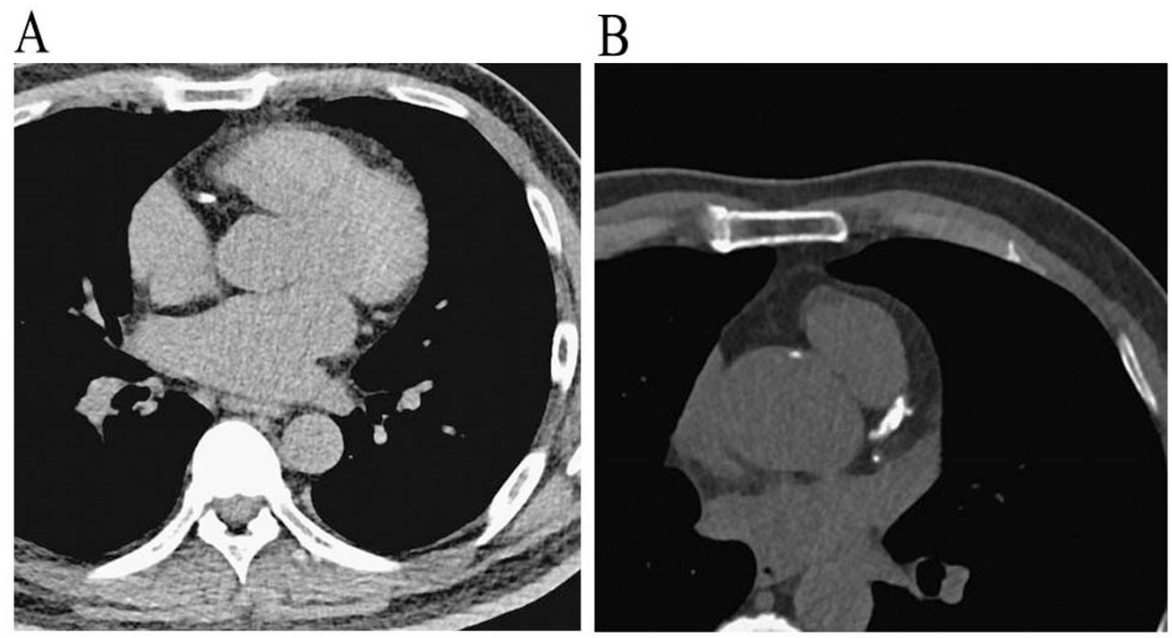

Figure 2. Coronary CT angiography results of coronary artery calcium score of 90.4(A) and 777.8 (B). 
descending branch lesions accounted for $73.6 \%$ (132 cases), and right coronary artery lesions accounted for 50.5\% (92 cases). $12 \%$ of the lesions were coronary bifurcation lesions, and $14 \%$ were chronic complete occlusions. Table 1 and Table 2 summarized the baseline data and angiographic characteristics of the patient study population. Further they were divided into MACCE group and Non-MACCE group according to the clinical outcome, that is, the occurrence of major cardiovascular and cerebrovascular events. The results showed that there were no statistically significant differences between the two groups in terms of gender, age, hypertension, diabetes, and medication use. In terms of SYNTAX score and SYNTAX score II, the MACCE group was significantly higher than the non-MACCE group, the difference was statistically significant.

\subsection{Score and grouping}

The SYNTAX integral distribution range was 1 to 43 (15.3 $\pm 10.7)$ scores, with a median of 12 in non-normal distribution. According to its frequency distribution, patients were divided into: low group $(1 \leq X<10, n=60)$, medium group $(10 \leq X<18$, $\mathrm{n}=60)$, high group $(18 \leq X, \mathrm{n}=62)$. calcium score distribution ranged from 0 to $1927(266.9 \pm 336.7)$ scores, with a median of 113 scores in non-normal distribution, according to their frequency distribution (Figure 3), patients were divided into: low group $(0 \leq X<89, n=62)$, medium group $(89 \leq X<287, n=60)$, high group $(287 \leq X, n=60)$. SYNTAX score II distribution ranged from 12.6 to $60.1(28.8 \pm 9.0)$, with a median of 28.4 , and was non-normally distributed. According to its frequency distribution, patients were divided into: low group $(1 \leq \mathrm{X}<24$, $\mathrm{n}=61)$, medium group $(24 \leq X<32, \mathrm{n}=61)$, high group $(32 \leq X$, $\mathrm{n}=60$ ). To determine whether the SYNTAX score combined with coronary calcium score can improve the accuracy of prediction, we established a SYNTAX score combined with coronary calcium score model based on the median of the two, and divided the patients into 3 groups: low-risk group (SYNTAX, Coronary artery calcium score $<113$ ), middle-risk group (SYNTAX $<12$, coronary artery calcium score $\geq 113$ or SYNTAX $>12$, coronary artery calcium score $\leq 113$ ), high-risk group (SYNTAX $\geq 12$ and coronary calcium score $\geq 113$ ).

\subsection{Clinical outcome}

During the follow-up period, the median follow-up time was 34.5 months, interquartile range: $26.7 / 42.1$. A total of 30 patients had MACCE with 12 deaths, 9 of them were cardiac deaths, 5 patients had myocardial infarction, and 14 patients underwent unplanned revascularization. After the above grouping, the results showed that in the SYNTAX score, coronary calcium score, SYNTAX score II and SYNTAX combined with coronary calcium score systems, the incidence of MACCE in the high-risk group was significantly higher than the medium-risk group and lowrisk group Outside the integral $(\mathrm{P}=0.176)$, the differences were statistically significant (SYNTAX integral: $\mathrm{P}=0.029$; SYNTAX

Table 1. Baseline characteristic of the study populations.

\begin{tabular}{|c|c|c|c|c|}
\hline \multirow{2}{*}{ Characteristics } & Total & Non-MACCE & MACCE & \multirow{2}{*}{$P$ value } \\
\hline & $(n=182)$ & $(n=152)$ & $(\mathrm{n}=30)$ & \\
\hline Age (years) & $68.4 \pm 9.4$ & $68.0 \pm 9.6$ & $70.5 \pm 8.2$ & 0.23 \\
\hline Male $[$ case $(\%)]$ & $130(71.4 \%)$ & $108(71.1 \%)$ & $22(73.3 \%)$ & 0.8 \\
\hline Body mass index $(\mathrm{kg} / \mathrm{m} 2)$ & $24.4 \pm 3.0$ & $24.4 \pm 3.1$ & $24.1 \pm 2.6$ & 0.3 \\
\hline Left ventricular ejection fraction(\%) & $63(60 / 66)$ & $63(60 / 66)$ & $63(60 / 66)$ & 0.68 \\
\hline Creatinine clearance $(\mathrm{ml} / \mathrm{min})$ & $76.6 \pm 24.0$ & $78.7 \pm 24.1$ & $66.2 \pm 21.0$ & $<0.01$ \\
\hline Diabetes (\%) & $49(26.9 \%)$ & $41(27.0 \%)$ & $8(26.7 \%)$ & 0.37 \\
\hline Hypertension (\%) & $137(75.2 \%)$ & $113(74.3 \%)$ & $24(80 \%)$ & 0.51 \\
\hline Abnormal blood lipid metabolism (\%) & $33(18.1 \%)$ & $27(17.8 \%)$ & $6(20 \%)$ & 0.77 \\
\hline Triglyceride (mmol/L) & $1.5 \pm 0.7$ & $1.5 \pm 0.7$ & $1.6 \pm 0.8$ & 0.72 \\
\hline Total cholesterol (mmol/L) & $4.0(3.2 / 5.0)$ & $4.0(3.3 / 4.7)$ & $4.2(3.2 / 5.4)$ & 0.51 \\
\hline High density lipoprotein (mmo/L) & $1.0(1.0 / 1.1)$ & $1.1(0.9 / 1.3)$ & $1.1(1.0 / 1.2)$ & 0.51 \\
\hline Low density lipoprotein (mmol/L) & $2.4 \pm 0.9$ & $2.3 \pm 0.9$ & $2.5 \pm 1.1$ & 0.55 \\
\hline Current smoking [cases (\%)] & $60(33 \%)$ & $46(30.1 \%)$ & $14(46.7 \%)$ & 0.08 \\
\hline SYNTAX & $12(8 / 21)$ & $11(8 / 20)$ & $17(13 / 23)$ & $<0.01$ \\
\hline SYNTAX II & $28(21.75 / 35)$ & $26.9(20.8 / 33)$ & 33. $(29.1 / 40)$ & $<0.01$ \\
\hline Calcium score & $113(61.8 / 339.5)$ & $110(57.8 / 322)$ & $227(106 / 614)$ & 0.02 \\
\hline Stable angina & $79(43.4 \%)$ & $68(44.8 \%)$ & $11(36.7 \%)$ & 0.42 \\
\hline Unstable angina & $83(45.6 \%)$ & $67(44.1 \%)$ & $16(53.3 \%)$ & 0.41 \\
\hline NSTEMI & $20(11 \%)$ & $17(11.2 \%)$ & $3(10 \%)$ & 0.78 \\
\hline Aspirin [cases (\%)] & $170(93.4 \%)$ & $141(92.7 \%)$ & $27(90 \%)$ & 0.51 \\
\hline Clopidogrel [cases (\%)] & $176(96.7 \%)$ & $143(94.6 \%)$ & $28(93.3 \%)$ & 0.59 \\
\hline ACEI/ARB [(\%)] & $61(33.5 \%)$ & $50(32.9 \%)$ & $11(36.7 \%)$ & 0.69 \\
\hline Beta blocker [case (\%)] & $54(29.7 \%)$ & $44(28.9 \%)$ & $10(33.3 \%)$ & 0.63 \\
\hline Statins $[$ cases $(\%)]$ & $127(69.8 \%)$ & $108(71 \%)$ & $19(63.3 \%)$ & 0.4 \\
\hline
\end{tabular}

ACEI: Angiotensin-converting enzyme inhibitors; ARB: Angiotensin receptor blockers. 
Table 2. Coronary angiography characteristics of the study population.

\begin{tabular}{|c|c|c|c|c|}
\hline Characteristics & $\begin{array}{c}\text { Total } \\
(n=182)\end{array}$ & $\begin{array}{c}\text { Non-MACCE } \\
(n=152)\end{array}$ & $\begin{array}{c}\text { MACCE } \\
(\mathrm{n}=30)\end{array}$ & $P$ value \\
\hline \multicolumn{5}{|l|}{ Number of lesions } \\
\hline Single-vessel lesion (\%) & $78(42.9 \%)$ & $68(44.7 \%)$ & $10(33.3 \%)$ & 0.25 \\
\hline Two-vessel lesions (\%) & $68(37.3 \%)$ & $58(38.2 \%)$ & $10(33.3 \%)$ & 0.62 \\
\hline Three-vessel disease (\%) & $36(19.8 \%)$ & $26(17.1 \%)$ & $10(33.3 \%)$ & 0.04 \\
\hline \multicolumn{5}{|l|}{ Lesion } \\
\hline Left trunk (\%) & $16(8.8 \%)$ & $12(7.9 \%)$ & $4(13.3 \%)$ & 0.26 \\
\hline Left anterior descending artery (\%) & $132(72.5 \%)$ & $109(71.7 \%)$ & $25(83.3 \%)$ & 0.99 \\
\hline Circumflex artery (\%) & $81(44.5 \%)$ & $61(40.1 \%)$ & $15(50 \%)$ & 0.99 \\
\hline Right coronary artery (\%) & $92(50.5 \%)$ & $74(48.7 \%)$ & $18(60 \%)$ & 0.1 \\
\hline \multicolumn{5}{|l|}{ Lesion characteristics } \\
\hline Bifurcation (\%) & $12(6.6 \%)$ & $10(6.6 \%)$ & $2(6.7 \%)$ & \\
\hline Chronic complete occlusion (\%) & $16(8.8 \%)$ & $13(8.6 \%)$ & $3(10 \%)$ & \\
\hline Number of stents inserted & $1(1 / 2)$ & $1(1 / 2)$ & $2(1 / 2)$ & \\
\hline
\end{tabular}

A

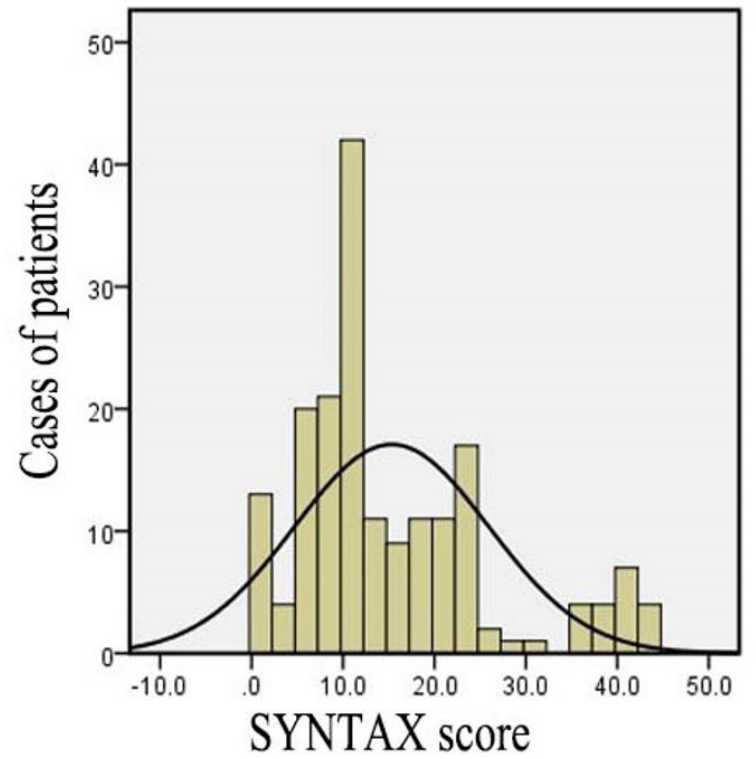

B

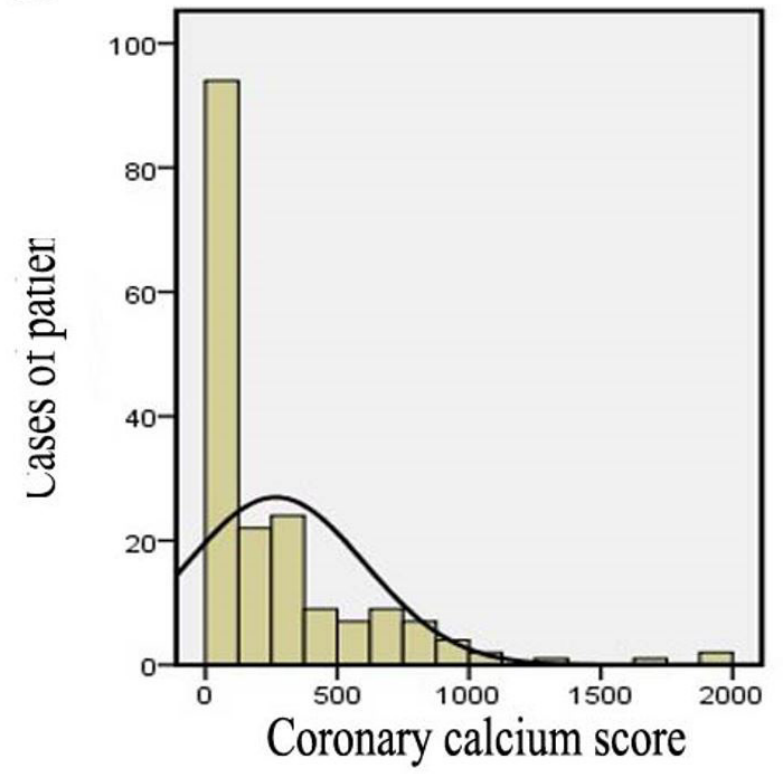

Figure 3. Distribution of SYNTAX score(A) and distribution of the coronary artery calcium score(B).

score II: $\mathrm{P}=0.012$; combined model: $\mathrm{P}<0.01)$. Further stratified analysis based on secondary outcome indicators showed that in the SYNTAX score and coronary calcium score, the incidence of non-fatal myocardial infarction in the high-risk group was higher than that in the low-risk group and the medium-risk group, and the difference was statistically significant. The incidence of all-cause death and myocardial infarction in the high-risk group of SYNTAX score II was higher than that in the low-risk group and the medium-risk group, and the difference was statistically significant. For the SYNTAX combined with coronary calcium score model, except for no significant statistical difference in stroke incidence, all other secondary outcome indicators, the incidence rate of the high-risk group was significantly higher than that of the low-risk group and the medium-risk group, and the difference was statistically significant (Table 3-6).

\subsection{Comparison of the predictive capabilities of various score systems}

The area under the ROC curve (AUC) of SYNTAX score, coronary artery calcium score, SYNTAX score II, SYNTAX combined with coronary calcium score were shown in Figure 4A: $0.641 \pm 0.052$ (95\% CI: 0.540-0.743), $0.597 \pm 0.055$ (95\% CI): 0.490-0.704), $0.662 \pm 0.052$ (95\% CI: 0.561-0.763), $0.711 \pm 0.053$ (95\% CI: 0.606-0.816). The SYNTAX score, coronary artery calcium score, and SYNTAX score II AUC were not significantly different from each other. The SYNTAX combined with coronary calcium score was statistically significant compared with the former three $(\mathrm{P}<0.01)$.

Further, the survival analysis of SYNTAX score combined with coronary calcium score was performed. The cumulative 
Original Article

Table 3. Clinical outcomes of PCI among SYNTAX score groups.

\begin{tabular}{|c|c|c|c|c|}
\hline Items & $\frac{\text { Low-risk }}{(\mathrm{n}=60)}$ & $\frac{\text { Medium-risk }}{(\mathrm{n}=60)}$ & $\begin{array}{c}\text { High-risk } \\
(\mathrm{n}=62)\end{array}$ & $P$ value \\
\hline MACCE & $4(6.7 \%)$ & $11(18.3 \%)$ & $15(24.2 \%)$ & 0.029 \\
\hline All-cause death & $1(1.7 \%)$ & $5(8.3 \%)$ & $6(9.7 \%)$ & 0.06 \\
\hline Cardiogenic death & $1(1.7 \%)$ & $5(8.3 \%)$ & $3(4.8 \%)$ & 0.282 \\
\hline Non-fatal myocardial infarction & $0(0 \%)$ & $1(1.7 \%)$ & $4(6.5 \%)$ & 0.037 \\
\hline Revascularization again & $2(3.3 \%)$ & $6(10 \%)$ & $6(9.7 \%)$ & 0.129 \\
\hline Stroke & $1(1.7 \%)$ & $0(0 \%)$ & $1(1.6 \%)$ & 0.659 \\
\hline
\end{tabular}

PCI: Percutaneous coronary intervention; MACCE: Major adverse cardiac and cerebrovascular events.

Table 4. Clinical outcomes of PCI among coronary calcium score groups.

\begin{tabular}{|c|c|c|c|c|}
\hline \multirow{2}{*}{ Items } & Low-risk & Medium-risk & High-risk & \multirow{2}{*}{$P$ value } \\
\hline & $(\mathrm{n}=62)$ & $(\mathrm{n}=60)$ & $(\mathrm{n}=60)$ & \\
\hline MACCE & $6(9.7 \%)$ & $11(18.3 \%)$ & $13(21.7 \%)$ & 0.176 \\
\hline All-cause death & $1(1.6 \%)$ & $5(8.3 \%)$ & $6(10 \%)$ & 0.05 \\
\hline Cardiogenic death & $0(0 \%)$ & $4(6.7 \%)$ & $5(8.3 \%)$ & 0.026 \\
\hline Non-fatal myocardial infarction & $0(0 \%)$ & $3(5 \%)$ & $2(3.3 \%)$ & 0.199 \\
\hline Revascularization again & $3(4.8 \%)$ & $4(6.7 \%)$ & $7(11.7 \%)$ & 0.108 \\
\hline Stroke & $2(3.2 \%)$ & $0(0 \%)$ & $0(0 \%)$ & 0.115 \\
\hline
\end{tabular}

PCI: Percutaneous coronary intervention; MACCE: Major adverse cardiac and cerebrovascular events.

Table 5. Clinical outcomes of PCI among SYNTAX II score groups.

\begin{tabular}{|c|c|c|c|c|}
\hline \multirow{2}{*}{ Items } & Low-risk & Medium-risk & High-risk & \multirow{2}{*}{$P$ value } \\
\hline & $(\mathrm{n}=61)$ & $(\mathrm{n}=61)$ & $(n=60)$ & \\
\hline MACCE & $4(6.6 \%)$ & $10(16.4 \%)$ & $16(26.7 \%)$ & 0.012 \\
\hline All-cause death & $2(3.3 \%)$ & $3(4.9 \%)$ & $7(11.7 \%)$ & 0.047 \\
\hline Cardiogenic death & $1(1.6 \%)$ & $3(4.9 \%)$ & $5(8.3 \%)$ & 0.069 \\
\hline Non-fatal myocardial infarction & $0(0 \%)$ & $1(1.6 \%)$ & $4(6.7 \%)$ & 0.022 \\
\hline Revascularization again & $1(1.6 \%)$ & $7(11.5 \%)$ & $6(10 \%)$ & 0.059 \\
\hline Stroke & $0(0 \%)$ & $1(1.6 \%)$ & $1(1.7 \%)$ & 0.33 \\
\hline
\end{tabular}

PCI: Percutaneous coronary intervention; MACCE: Major adverse cardiac and cerebrovascular events.

Table 6. Clinical outcomes of PCI among SYNTAX combined with coronary calcium groups.

\begin{tabular}{|c|c|c|c|c|}
\hline \multirow{2}{*}{ Items } & Low-risk & Medium-risk & High-risk & \multirow{2}{*}{$P$ value } \\
\hline & $(\mathrm{n}=52)$ & $(\mathrm{n}=74)$ & $(n=56)$ & \\
\hline MACCE & $4(7.7 \%)$ & $6(8.1 \%)$ & $20(35.8 \%)$ & $<0.01$ \\
\hline All-cause death & $1(1.9 \%)$ & $2(2.7 \%)$ & $9(16.1 \%)$ & $<0.01$ \\
\hline Cardiogenic death & $1(1.9 \%)$ & $1(1.4 \%)$ & $7(12.5 \%)$ & $<0.01$ \\
\hline Non-fatal myocardial infarction & $0(0 \%)$ & $0(0 \%)$ & $5(8.9 \%)$ & $<0.01$ \\
\hline Revascularization again & $2(3.8 \%)$ & $3(4.1 \%)$ & $9(16.1 \%)$ & 0.012 \\
\hline Stroke & $1(1.9 \%)$ & $1(1.4 \%)$ & $0(0 \%)$ & 0.314 \\
\hline
\end{tabular}

PCI: Percutaneous coronary intervention; MACCE: Major adverse cardiac and cerebrovascular events.

probability of MACCE not occurring during follow-up in the low-risk group was $92.0 \%, 88.6 \%$, and $63.9 \%$ in the low-risk group, the difference was statistically significant $(\mathrm{P}<0.01$, Figure $4 \mathrm{~B})$.

\section{Discussion}

Coronary artery interventional therapy is an important way of coronary revascularization in patients with coronary heart disease, and it plays a vital role in the treatment of patients with coronary heart disease. However, it is still controversial whether patients with extensive coronary lesions and severe lesions can benefit from PCI treatment. Risk scores can be used to predict the incidence of major adverse cardio-cerebrovascular events after PCI, and then to identify high-risk populations to provide a reference for patients with coronary heart disease to choose appropriate revascularization methods. The SYNTAX score and the SYNTAX score II included in clinical variables are two commonly used risk assessment systems based on coronary angiography. Several studies have reported that they can predict the incidence of MACCE (Serruys et al., 2019; Mohr et al., 
A

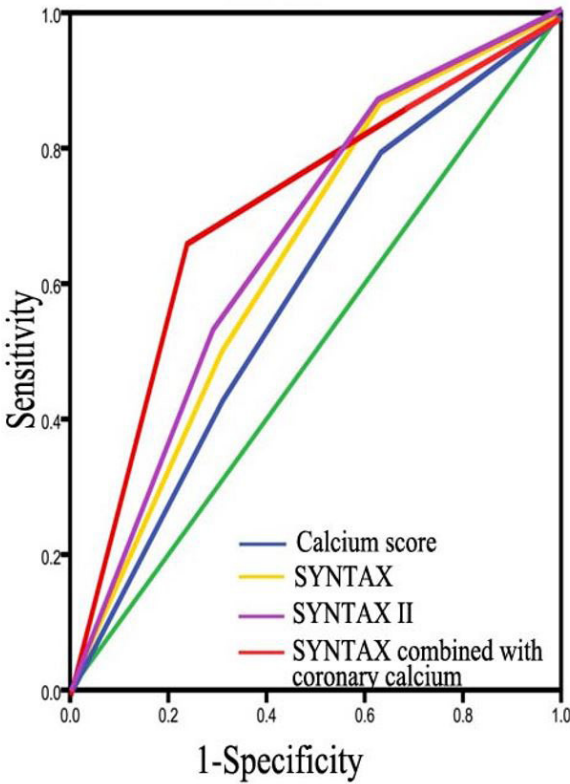

B

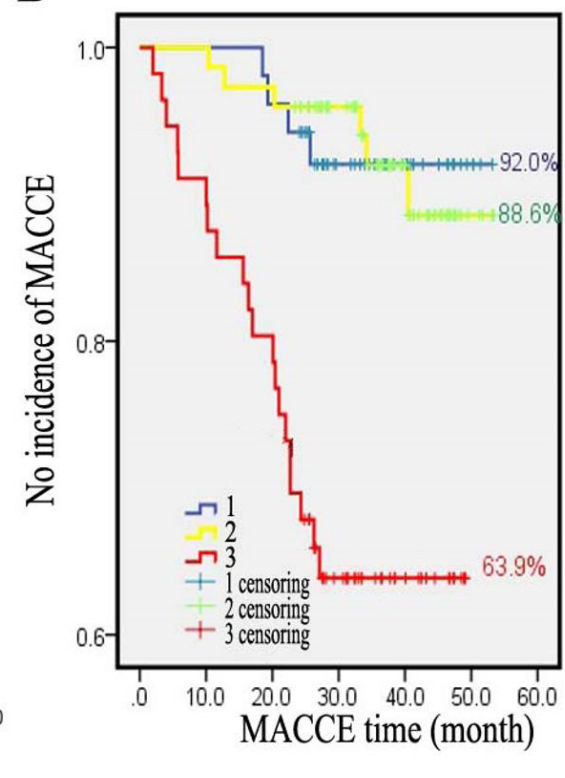

Figure 4. Area under ROC curve of coronary calcium score, SYNTAX score, SYNTAX II score, and SYNTAX combined with coronary calcium score (A). Kaplan-Meier curve of cumulative MACCE of SYNTAX combined with coronary calcium score(B).

2013). Coronary calcium is one of the important risk factors for adverse cardio-cerebrovascular events. Therefore, it is proposed that coronary calcium score can be used to evaluate the degree of calcium and predict the incidence of MACCE (Madhavan et al., 2014). However, most of the research on the above-mentioned integral system was from abroad, and there were still few domestic studies, and the study excluded patients with single-vessel or two-vessel disease. Therefore, PCI patients based on the Chinese population were evaluated the prediction of cardio-cerebrovascular events after PCI with SYNTAX score, SYNTAX score II and coronary calcium score in patients with coronary heart disease (including single coronary, two- and three-vessel vascular disease) value. At the same time, coronary angiography imaging analysis was less sensitive to calcified lesions than coronary CT and cannot be quantified. Therefore, a new model of SYNTAX score combined with coronary calcium score was established to stratify patients.

Our study found that after 182 patients with coronary heart disease undergoing PCI treatment were classified into low-risk, medium-risk, and high-risk groups based on SYNTAX score and SYNTAX score II, the incidence of MACCE was 6.7\%, 18.3\%, $24.2 \% ; 26.7 \%$, and there are statistical differences between the groups, consistent with previous results (Sinning et al., 2013; Martins et al., 2019), suggesting that the SYNTAX score and SYNTAX score II can be used as a risk score tool for coronary heart disease patients after PCI and predict MACCR incidence. However, this study did not find a significant statistical difference in the incidence of MACCE between different groups of coronary calcium scores. The reasons for consideration may be: 1) Current studies on coronary calcium scores were mostly inconsistent with the risk grouping criteria. For example, they were classified into low, medium and high-risk groups according to the calcium score of 0, 0-400,> 400 (Xie et al., 2016), and were grouped according to the standard of calcium score $\leq 300,300-1000,>1000$ (Detrano et al., 2008). This study was mainly grouped according to the tertile grouping. 2) Patients with coronary heart disease had non-calcified plaques, especially young people. Rupture of non-calcified soft plaques can increase cardiovascular events (Kim et al., 2012). 3) The sample size of this study was relatively small, and it was also related to the single-center clinical study.

According to the subgroup analysis of secondary outcome indicators, we found that the SYNTAX score II in the low-risk, medium-risk, and high-risk groups had statistically significant differences in all-cause mortality and the incidence of myocardial infarction. The SYNTAX score was only in non-fatal myocardial infarction, and there was a statistically significant difference in incidence. In a prospective cohort study in 2009, 528 PCI patients with unprotected left main lesions were included. The predictive power of SYNTAX score II was better than SYNTAX score for postoperative atrial fibrillation (Ozturk et al., 2019). However, the results of this study showed that the areas under the ROC curve of SYNTAX score and SYNTAX score II under MACCE were 0.641 and 0.642 , respectively, and there was no statistical difference between the two. Therefore, it was suggested that for PCI patients with non-main disease, the SYNTAX score II may not improve the accuracy of prediction. However, it is worth noting that the proportion of elderly and renal insufficiency patients included in this study was relatively small, suggesting that the research population with clinical characteristics of lowto-moderate risk may be an important reason for this result.

We established a SYNTAX score combined with coronary calcium score risk assessment model, and redefined the low-risk, medium-risk, and high-risk groups. The results of the study showed that the incidence of MACCE in the low, medium, and 
high-risk groups were $7.7 \%, 8.1 \%$, and $35.8 \%$, respectively, and the difference was statistically significant $(\mathrm{P}<0.01)$. Moreover, for all secondary outcome indicators, except for stroke, the incidence of adverse events in the high-risk group was significantly higher than that in the low-risk group and the medium-risk group. The results were statistically different, suggesting that the joint integral model has a strong ability to evaluate clinical prognosis. Martin-Reyes et al. (2015) incorporated 270 patients with acute coronary syndrome and established SYNTAX score combined with coronary calcium score. The study found that SYNTAX> 14 score combined with moderate and severe calcium can effectively predict the thrombotic events after acute coronary syndrome occurred. Comparing the predictive ability of the joint integral model with the SYNTAX integral., SYNTAX II integral., and coronary calcium score, the area under the ROC curve of MACCE was 0.717 , which was the largest. The prediction ability of MACCE may be more accurate.

This study observed that the SYNTAX score combined with the coronary calcium score model had a strong ability to predict clinical events. We speculated that the reasons were as follows: 1) Some studies had expressed strong predictive value through conventional risk factors combined with the coronary calcium score model, and observed that the area under the curve (AUC) had increased significantly (Lau et al., 2012; Kwon et al., 2011). A large domestic study had shown that coronary CT imaging combined with the coronary calcium score model can significantly increase the predictive value of coronary heart disease adverse events. The area under the ROC curve ranged from 0.82 to 0.93 $(\mathrm{p}<0.001)$ (Hou et al., 2012). Therefore, it can be considered that the combined coronary calcium integral model may have strong predictive value. 2) The high value of SYNTAX reflects the severe anatomical coronary lesions, and the coronary calcium score indicated the presence of calcified plaque in the coronary intima. Clinically, for patients with severe coronary artery disease and severe calcified lesions, it will first reduce the surgeon's ability to judge the coronary artery, and the difficulty and risk of surgery increase. Secondly, severe calcified lesions will lead to poor stent passability during surgery, postoperative coronary dissection, postoperative acute stent thrombosis caused by incomplete stent release or poor stent adherence may increase the incidence of postoperative clinical adverse events (Martin-Reyes et al., 2015). For these patients, the use of intraoperative myocardial blood flow reserve fraction (FFR), intravascular ultrasound (IVUS), and second-generation drug stents to reduce postoperative adverse events require further research. 3) Study had shown that coronary calcium score was an independent predictor of stroke (Kong et al., 2018). The high value of coronary calcium score was related to ischemic stroke (Kim et al., 2010), and there was significant progress in coronary calcium score in patients with diabetic nephropathy (Mehrotra et al., 2005). Therefore, it can be considered that the increase of coronary calcium score may prompt the decline of other organ functions, which in turn increased the risk of long-term adverse events in these patients.

However, this study also has certain limitations. This study is a retrospective cohort study. The sample size included in the study is limited, which has a certain impact on the reliability of the results. We mainly use the area under the ROC curve to compare the different integral systems to evaluate the predictive value.
However, the ROC curve is mainly used for diagnostic research, but it is still used by many similar institutes clinically because of its simplicity and reliability. Another potential shortcoming is that the patient 's self-reported risk factors can cause recall bias. The lack of continuous risk variables during follow-up may reduce the accuracy of the risk assessment. Therefore, a large sample, multicenter prospective study is still needed to confirm the ability of SYNTAX combined with coronary calcium score to predict the prognosis of patients with coronary heart disease after PCI.

\section{References}

Al Rifai, M., McEvoy, J. W., Nasir, K., Rumberger, J., Feldman, D., Budoff, M. J., \& Blaha, M. J. (2015). Traditional cardiovascular disease risk factors associated with one-year all-cause mortality among those with coronary artery calciumscores $\geq 400$. Atherosclerosis, 241(2), 495-497. http://dx.doi.org/10.1016/j.atherosclerosis.2015.06.002. PMid:26091973.

Choi, K. H., Song, Y. B., Lee, J. M., Lee, S. Y., Park, T. K., Yang, J. H., Choi, J. H., Choi, S. H., Gwon, H. C., \& Hahn, J. Y. (2019). Impact of intravascular ultrasound-guided percutaneous coronary intervention on long-term clinical outcomes in patients undergoing complex procedures. JACC: Cardiovascular Interventions, 12(7), 607-620. http://dx.doi.org/10.1016/j.jcin.2019.01.227. PMid:30878474.

Clerc, O.F., Caobelli, F., Haaf, P., Zellweger, M.J. (2020). 1172 Predictive value of coronary artery calcium score for myocardial ischaemia in positron emission tomography. Eur Heart J Cardiov Imaging, (Suppl. 1):

Detrano, R., Guerci, A. D., Carr, J. J., Bild, D. E., Burke, G., Folsom, A. R., Liu, K., Shea, S., Szklo, M., Bluemke, D. A., O’Leary, D. H., Tracy, R., Watson, K., Wong, N. D., \& Kronmal., R. A. (2008). Coronary calcium as a predictor of coronary events in four racial or ethnic groups. The New England Journal of Medicine, 358(13), 1336-1345. http://dx.doi.org/10.1056/NEJMoa072100. PMid:18367736.

Farooq, V., van Klaveren, D., Steyerberg, E. W., Meliga, E., Vergouwe, Y., Chieffo, A., Kappetein, A. P., Colombo, A., Holmes, D. R. Jr, Mack, M., Feldman, T., Morice, M. C., Ståhle, E., Onuma, Y., Morel, M., Garcia-Garcia, H. M., van Es, G. A., Dawkins, K. D., Mohr, F. W., \& Serruys, P. W. (2013). Anatomical and clinical characteristics to guide decision making between coronary artery bypass surgery and percutaneous coronary intervention for individual patients: development and validation of SYNTAX score II. Lancet, 381(9867), 639-650. http://dx.doi.org/10.1016/S0140-6736(13)60108-7. PMid:23439103.

Greenland, P., LaBree, L., Azen, S., Doherty, T., \& Detrano, R. (2004). Coronary artery calcium score combined with framingham score for risk prediction in Asymptomativ Individuals. Journal of the American Medical Association, 291(2), 210-215. http://dx.doi.org/10.1001/ jama.291.2.210. PMid:14722147.

Hogan, A., Ibrahim, S., Moylan, M., McCormack, D., Openshaw, A. M., Cormack, F., \& Shipolini, A. (2020). Five year follow-up of undiagnosed sleep apnea in patients undergoing coronary artery bypass graft surgery. The Journal of Cardiovascular Surgery, 61(5), 648-656. http://dx.doi.org/10.23736/S0021-9509.20.11200-X.

Hou, Z. H., Lu, B., Gao, Y., Jiang, S. L., Wang, Y., Li, W., \& Budoff, M. J. (2012). Prognostic value of coronary CT Angiography and calcium score for major adverse cardiac events in outpatients. JACC: Cardiovascular Imaging, 5(10), 990-999. http://dx.doi.org/10.1016/j. jcmg.2012.06.006. PMid:23058065. 
Ikeno, F., Brooks, M. M., Nakagawa, K., Kim, M. K., Kaneda, H., Mitsutake, Y., Vlachos, H. A., Schwartz, L., Frye, R. L., Kelsey, S. F., Waseda, K., Hlatky, M. A., Detre, K. M., Kelsey, S. F., Brooks, M. M., Orchard, T. J., Thomas, S. B., Tyrrell, K. S., Rana, J. S., Averbach, F., MacGregor, J. M., O’Neal., S. M., Pitluga, K., Sansing, V., Tranchine, M., Crow, S. W., Bertolet, M. M., Hardison, R., Kip, K., Lombardero, M., Lu, J., Janiszewski, S., Protivnak, D., Reiser, S., Barton, S., Guo, P., Kushner, Y., Michael, O., Martin, J. P., Kania, C., Kania, M., O’Donnell, J., Maxwell, R. A., Frye, R. L., Goldberg, S., Rosenberg, Y., Desvigne-Nickens, P., Ershow, A., Gordon, D., Paltoo, D., Jones, T. L. Z., Hueb, W., Ramires, J., Lopes, N., Wajchenberg, B. L., Martinez, E. E., Oliveira, S. A., Ribeiro, E. E., Perin, M., Betti, R., Schwartz, L., Steiner, G., Barolet, A., Groenewoud, Y., Mighton, L., Camelon, K., O’Rourke, R., Blodgett, J., Sako, E., Nicastro, J., Prescott, R., Rihal., C., Kennedy, F., Barsness, G., Basu, A., Clavell, A., Frye, R., Holmes, D. R. Jr, Lerman, A., Mullaney, C., Reeder, G., Rizza, R., Schaff, H., Smith, S., Somers, V., Sundt, T., Ting, H., Wright, R. S., Helgemoe, P., Lesmeister, D., Rolbiecki, D., LepeMontoya, L., Escobedo, J., Barraza, R., Baleón, R., Campos, A., García, P., Lezama, C., Miramontes, C., Ocampo, S., Peñafiel, J. V., Valdespino, A., Verdín, R., Albarrán, H., Ayala, F., Chávez, E., Murillo, H., Buitrón, L. V., Rico-Verdin, B., Angulo, F., Adler, D., Halle, A. A., Ismail-Beigi, F., Paranjape, S., Mazzurco, S., Ridley, K., Ramanathan, K., Solomon, S., Wall, B., Weinman, D., Touchstone, T., Douglas, L., Bourassa, M., Tardif, J.-C., Chiasson, J.-L., Lavoie, M. A., Rabasa-Lhoret, R., Langelier, H., Foucher, S., Trudel, J., Monrad, S., Srinivas, V., Zonszein, J., Crandall, J., Duffy, H., Vartolomei, E., King, S. $3^{\text {rd }}$, Jacobs, C., Robertson, D., Porter, M., Eley, M., Nichols, E., LaCorte, J., Mock, M., Rogers, W., Ovalle, F., Bell, D., Misra, V. K., Hillegass, W. B., Aqel, R., Pierce, P., Smith, M., Saag, L., Vaughn, A., Smith, D., Grimes, T., Rolli, S., Hill, R., Barrett, B. D., Morehead, C., Doss, K., Davidson, C. J., Molitch, M., Beohar, N., Massaro, E., Goodreau, L., Arroyo, F., Neužil, P., Pavlickova, L., Stehlíková, Š., Benedik, J., Coling, L., Davies, R., Glover, C., LeMay, M., Mesana, T., Ooi, T. C., Silverman, M., Sorisky, A., Favreau, C., McClinton, S., Weiss, M., Weiss, I., Saulle, L., Kannam, H., Kurylas, J. C., Vasi, L., Douglas, J. Jr, Ghazzal., Z., Sperling, L., King, S. $3^{\text {rd }}$, Dayamani, P., Gebhart, S., Basu, S., Helmy, T., Tangpricha, V., Hyde, P., Jenkins, M., Grant, B. P., Kent, K., Suddath, W., Magee, M., Julien-Williams, P., Reed, V., Nassar, C., Dagenais, G., Garceau, C., Auger, D., Buller, C., Elliott, T., Ramanathan, K., Ricci, D., Fox, R., Kolesniak, D., Attubato, M., Feit, F., Richardson, S., Sing, I. P., Slater, J., Amendola, A., Vargas, B., Tsapatsaris, N., Woods, B., Cushing, G., Rutter, M., Singh, P., DesRochers, G., Woodhead, G., Gannon, D., Campbell, N. S., Ragosta, M., Sarembock, I., Powers, E., Barrett, E., Jahn, L., Murie, K., Das, G., Sigurdsson, G., White, C., Bantle, J., Redmon, J. B., Kwong, C., Tamis-Holland, J., Albu, J., Hochman, J. S., Slater, J., Wilentz, J., Frances, S., Tormey, D., Pepine, C., Smith, K., Kennedy, L., Brezner, K., Curry, T., Bleyer, F., Albert, S., Mooradian, A., Plummer, S., Fuentes, F., Robles, R., Lavis, V., Gomez, J., Iliescu, C., Underwood, C., Fulton, M. S., Ramirez, J. G., Merta, J., Scott, G., Krishnaswami, A., Dowdell, L., Berkheimer, S., Greenbaum, A., Whitehouse, F., Pangilinan, R., Mann, K., Jacobs, A. K., Sternthal., E., Ebner, S., Nedeljkovic, Z., Beardsley, P., Schneider, D., Pratley, R., Cefalu, W., Schnure, J., Rowen, M., Tilton, L., Niederman, A., Mata, C., Kellerman, T., Farmer, J., Garber, A. J., Kleiman, N., Howard, N., Nichols, D., Pool, M., Granger, C., Feinglos, M., Adams, G., Green, J., Druken, B., Underwood, D., Stafford, J. L., Donner, T., Laskey, W., Beach, D., Lopez, J., Davis, A., Faxon, D., Reutrakul, S., Bayer, E., Marroquin, O., Cohen, H., Korytkowski, M., Koerbel, G., Baxendell, L., Rosenfelder, D., DeRiso, L., Farrell, C., Vita, T., McGill, J., Krone, R., Bach, R., Recklein, C., Luepke, K. M., Clifton, M. J., Farkouh, M. E., Kim, M. C., Smith, D. A., Guzman, I., Travis, A., O’Keefe, J., Forker, A., Isley, W., Moe, R., Kennedy, P., Rosson, M., Long, A.,
Bates, E., Herman, W., Pop-Busui, R., Duvernoy, C., Stevens, M., Luciano, A., Majors, C., Gottlieb, S. H., Rodriguez, A., Herr, M., Williams, D., Smith, R. J., Abbott, J. D., Laufgraben, M. J., Grogan, M., Muratori, J., Habib, G., Marcelli, M., Mikati, I., Cordero, E., Caldwell, G., Schechter, D., Lorber, D., August, P., Brown, M., Depree, P., Huber, K., Hanusch-Enserer, U., Jordanova, N., Cilesiz, D., Vogel, B., McCallister, B. Jr, Kleerekoper, M., Mandagere, K., Urbanic, R., Bengston, J., Kong, B. K., Pruitt, A., Sanfield, J., Carulli, C., ChurleyStrom, R., Magorien, R., Osei, K., Boyer, C. C., Lee, R., Palumbo, P., Wisbey, J., Alderman, E., Ikeno, F., Michael Steffes, A. S., Nowicki, M., Bucksa, J., Chaitman, B., Eckstein, J., Stocke, K., Hlatky, M. A., Boothroyd, D. B., Melsop, K. A., Sobel, B. E., Rowen, M., Neimane, D., Iskandrian, A. E., Schaaf, M. B., Genuth, S., Bongarno, T., Nesto, R., August, P., Hultberg, K., Gottlieb, S. H., Albu, J., RosenhouseRomeo, H., Orchard, T. J., Pambianco, G., Lombardero, M., Mock, M., Frye, R. L., Brooks, M. M., Desvigne-Nickens, P., Ershow, A., Genuth, S., Goldberg, S., Gordon, D., Hardison, R., Jones, T. L. Z., Kelsey, S., Nesto, R., Orchard, T., Paltoo, D., Rosenberg, Y., Ryan, T., Lebovitz, H., Brown, R., Friesinger, G., Horton, E., Mason, J., Virmani, R., Wechsler, L., Bairey-Merz, C. N., Kennedy, J. W., Gordon, D., Antman, E., Colwell, J., Fowler, S., Furberg, C., Goldman, L., Jennings, B., \& Rankin, S., and the BARI-2D Study Group (2017). SYNTAX score and long-term outcomes: the BARI-2D trial. Journal of the American College of Cardiology, 69(4), 395-403. http://dx.doi. org/10.1016/j.jacc.2016.10.067. PMid:28126156.

Karabağ, Y., Çağdaş, M., Rencuzogullari, I., Karakoyun, S., Artaç, İ., İliş, D., Yesin, M., Öterkus, M., Gokdeniz, T., Burak, C., \& Tanboğa, I. (2018). Comparison of SYNTAX score II efficacy with SYNTAX score and TIMI risk score for predicting in-hospital and long-term mortality in patients with ST segment elevation myocardial infarction. The International Journal of Cardiovascular Imaging, 34(8), 11651175. http://dx.doi.org/10.1007/s10554-018-1333-1. PMid:29541904.

Kim, B. J., Choi, S. Y., Lee, S. H., Kim, C. K., Ryu, W. S., Han, M. K., Oh, B. H., Bae, H. J., \& Yoon, B. W. (2010). Advanced coronary artery calcification is associated with ischemic stroke. Cerebrovascular Diseases (Basel, Switzerland), 30(1), 93-100. http://dx.doi. org/10.1159/000314711. PMid:20501993.

Kim, Y., Hur, J., Lee, H. J., Chang, H. J., Nam, J., Hong, Y., Kim, H. Y., Lee, J., \& Choi, B. W. (2012). Meaning of zero coronary calcium score in symptomatic patients referred for coronary computed tomographic angiography. European Heart Journal Cardiovascular Imaging, 13(9), 776-785. http://dx.doi.org/10.1093/ehjci/jes060. PMid:22461571.

Kong, W. Y., Eide, S. E., Ngiam, N., Yuan, C. H., Tan, D. Y. C., Yang, O. H., Sunny, S., Tan, B. Y. Q., Sharma, V. K., Chan, B., \& Yeo, L. L. L. (2018). CT Brain calcium score predicts recurrent transient ischaemic attack or stroke in patients with first presentation of transient ischaemic Attack. Neurology, 90(15, Supplement)

Kwon, S. W., Kim, Y. J., Shim, J., Sung, J. M., Han, M. E., Kang, D. W., Kim, J. Y., Choi, B. W., \& Chang, H. J. (2011). Coronary artery calcium scoring does not add prognostic value to standard 64-section CT angiography protocol in low-risk patients suspected of having coronary artery disease. Radiology, 259(1), 92-99. http://dx.doi. org/10.1148/radiol.10100886. PMid:21324842.

Lau, K. K., Wong, Y. K., Chan, Y. H., Yiu, K. H., Teo, K. C., Li, L. S. W., Ho, S. L., Chan, K. H., Siu, C. W., \& Tse, H. F. (2012). Prognostic implications of surrogate markers of atherosclerosis in low to intermediate risk patients with Type 2 Diabetes. Cardiovascular Diabetology, 11(1), 101. http://dx.doi.org/10.1186/1475-2840-11101. PMid:22900680.

Madhavan, M. V., Tarigopula, M., Mintz, G. S., Maehara, A., Stone, G. W., \& Généreux, P. (2014). Coronary artery calcification: Pathogenesis and prognostic implications. Journal of the American 
College of Cardiology, 63(17), 1703-1714. http://dx.doi.org/10.1016/j. jacc.2014.01.017. PMid:24530667.

Malakar, A., Choudhury, D., Halder, B., Paul, P., Uddin, D. A., \& Chakraborty, S. (2019). A review on coronary artery disease, its risk factors, and therapeutics. Journal of Cellular Physiology, 234(10), 234. http://dx.doi.org/10.1002/jcp.28350. PMid:30790284.

Martin-Reyes, R., Franco Pelaez, J. A., Carda, R., Lazaro, A., Aceña, A., Lorenzo, O., Martín-Ventura, J., Blanco-Colio, L., Rios, J., \& Tunón, J. (2015). TCT-282 The combination of high Syntax Score and moderate to severe Coronary Artery Calcification is a strong predictor of thrombotic events after an Acute Coronary Syndrome. Journal of the American College of Cardiology, 66(15), B110-B111. http://dx.doi.org/10.1016/j.jacc.2015.08.296.

Martins, E. B., Hueb, W., Lima, E. G., Rezende, P. C., Garzillo, C. L., Carvalho, G. F., Carvalho, F. P. C., Linhares Fo., J. P. P., Batista, D. V., Silva, R. R., Boros, G. A. B., Azevedo, D. F. C., Serrano, C. V. Jr., Ramires, J. A. F., \& Filho, R. K. (2019). P1835Application of SYNTAX score I, II and residual SYNTAX as predictors of long-term clinical outcomes after coronary artery bypass grafting. European Heart Journal., 40(Suppl. 1), 1. http://dx.doi.org/10.1093/eurheartj/ ehz748.0587.

Matsuo, N., Hayashi, K., Katou, Y., Hasegawa, M., Tanimoto, M., Fujiwara, T., Kagawa, K., Nakano, Y., Oonishi, N., Takaishi, A., Hirohata, S., \& Ueeda, M. (2018). Supplementation of Omega-3 PUFAs could improve long term prognosis after PCI in patients without hyperlipidemia and diabetes. Atherosclerosis, 275, e73-e74. http://dx.doi.org/10.1016/j.atherosclerosis.2018.06.206.

Mehrotra, R., Budoff, M., Hokanson, J. E., Ipp, E., Takasu, J., \& Adler, S. (2005). Progression of coronary artery calcification in diabetics with and without chronic kidney disease. Kidney International., 68(3), 1258-1266. http://dx.doi.org/10.1111/j.1523-1755.2005.00522.x. PMid:16105059.

Mizuiri, S., Nishizawa, Y., Yamashita, K., Mizuno, K., Ishine, M., Doi, S., Masaki, T., \& Shigemoto, K. (2018). Coronary artery calcification score and common iliac artery calcification score in non-dialysis CKD patients. Nephrology (Carlton, Vic.), 23(9), 837-845. http:// dx.doi.org/10.1111/nep.13113. PMid:28703899.

Mohr, F., Morice, M. C., Kappetein, A., Feldman, T., Ståhle, E., Colombo, A., Mack, M., Holmes, D. Jr, Morel, M., Dyck, N., Houle, V., Dawkins, K., \& Serruys, P. (2013). Coronary artery bypass graft surgery versus percutaneous coronary intervention in patients with three-vessel disease and left main coronary disease: 5-Year follow-up of the randomised, clinical SYNTAX trial. Lancet, 381(9867), 629-638. http://dx.doi.org/10.1016/S0140-6736(13)60141-5. PMid:23439102.

Na, X., Tang, X. F., Yi, Y., Zhao, X. Y., Chen, J., Gao, Z., Qiao, S. B., Yang, Y. J., Gao, R. L., Bo, X., \& Yuan, J. Q. (2018). Association of Plasma Lipoprotein(a) with long-term adverse events in patients with chronic kidney disease who underwent percutaneous coronary intervention. The American Journal of Cardiology, 122(12), 20432048. PMid:30477725.

Ozturk, S., Kalyoncuoglu, M., \& Sahin, M. (2019). Comparison of SYNTAX Score I and SYNTAX Score II for Predicting postoperative atrial fibrillation in patients undergoing coronary artery bypass graft surgery. The Heart Surgery Forum, 22(5), E319-E324. http://dx.doi. org/10.1532/hsf.2495. PMid:31596705.
Serruys, P. W., Morice, M. C., Kappetein, A. P., Colombo, A., Holmes, D. R., Mack, M. J., Ståhle, E., Feldman, T. E., Marcel, V. D. B., Bass, E. J., Van Dyck, N., Leadley, K., Dawkins, K. D., \& Mohr, F. W. (2009). Percutaneous coronary intervention versus coronary-artery bypass grafting for severe coronary artery disease. The New England Journal of Medicine, 360(10), 961-972. http://dx.doi.org/10.1056/ NEJMoa0804626. PMid:19228612.

Serruys, P. W., Kogame, N., Katagiri, Y., Modolo, R., Buszman, P. E., Íñiguez-Romo, A., Goicolea, J., Hildick-Smith, D., Ochala, A., Dudek, D., Piek, J. J., Wykrzykowska, J. J., Escaned, J., Banning, A. P., Farooq, V., \& Onuma, Y. (2019). Clinical outcomes of state-ofthe-art percutaneous coronary revascularization in patients with three-vessel disease: 3-year follow-up of the SYNTAX II study. European Heart Journal., 15(3), e244-e252. PMid:30636684.

Sianos, G., Morel, M. A., Kappetein, A. P., Morice, M. C., Colombo, A., Dawkins, K., van den Brand, M., Van Dyck, N., Russell, M. E., Mohr, F. W., \& Serruys, P. W. (2005). The SYNTAX Score: An angiographic tool grading the complexity of coronary artery disease. EuroIntervention, 1(2), 219-227. PMid:19758907.

Sinning, J., Asdonk, T., Erlhöfer, C., Vasa-Nicotera, M., Grube, E., Nickenig, G., \& Werner, N. (2013). Combination of angiographic and clinical characteristics for the prediction of clinical outcomes in elderly patients undergoing multivessel PCI. Clinical Research in Cardiology; Official Journal of the German Cardiac Society, 102(12), 865-873. http://dx.doi.org/10.1007/s00392-013-0599-5. PMid:23881543.

Wijns, W., Kolh, P., Danchin, N., Mario, C. D., Falk, V., Folliguet, T., Garg, S., Huber, K., James, S., Knuuti, J. M., López-Sendón, J., Marco, J., Menicanti, L., Ostojic, M., Piepoli, M., Pirlet, C., Pomar, J. L., Reifart, N., Ribichini, F., Schalij, M. J., Sergeant, P., Serruys, P. W., Silber, S., Uva, M. S., \& Taggart, D. (2010). Guidelines on myocardial revascularization. Revista Portuguesa de Cardiologia, 31(20), 2501-2555. PMid:20802248.

Xie, Q., Ge, X., Shang, D., Li, Y., Yan, H., Tian, J., Hao, C. M., \& Zhu, T. (2016). Coronary artery calcification score as a predictor of allcause mortality and cardiovascular outcome in peritoneal dialysis patients. Peritoneal Dialysis International., 36(2), 163-170. http:// dx.doi.org/10.3747/pdi.2014.00124. PMid:26224787.

Xu, B., Généreux, P., Yang, Y., Leon, M., Xu, L., Qiao, S., Wu, Y., Yan, H., Chen, J., Zhao, Y., Zhao, Y., Palmerini, T., Stone, G., \& Gao, R. (2014). Validation and Comparison of the long-term prognostic capability of the SYNTAX Score-II Among 1,528 Consecutive patients who underwent left main percutaneous coronary intervention. JACC: Cardiovascular Interventions, 7(10), 1128-1137. http://dx.doi. org/10.1016/j.jcin.2014.05.018. PMid:25240551.

Yancy, C. W., Jessup, M., Bozkurt, B., Butler, J., Casey, D. E. Jr, Drazner, M. H., Fonarow, G. C., Geraci, S. A., Horwich, T., Januzzi, J. L., Johnson, M. R., Kasper, E. K., Levy, W. C., Masoudi, F. A., McBride, P. E., McMurray, J. J. V., Mitchell, J. E., Peterson, P. N., Riegel, B., Sam, F., Stevenson, L. W., Tang, W. H. W., Tsai, E. J., \& Wilkoff, B. L., and the American College of Cardiology Foundation (2013). American college of cardiology foundation; American Heart Association Task Force on Practice Guidelines. 2013 ACCF/AHA guideline for the management of heart failure: A report of the American College of Cardiology Foundation/American Heart Association Task. Circulation, 128(16), e240-e319. http://dx.doi.org/10.1161/ CIR.0b013e31829e8776. PMid:23741058. 